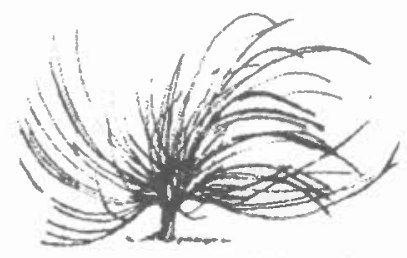

\title{
El alma del barrio
}

Ingrid Madrigal Vindas ${ }^{I}$ Universidad Nacional, Costa Rica

Heredia, Costa Rica

ingrita62@yahoo.com

\section{Resumen}

Esta vivencia trata sobre los recuerdos y añoranzas de un "Barrio", lo que sirve de hilo conductor para desarrollar una reflexión personal sobre los cambios socioculturales, es decir, del modo de vida, que se han dado en la sociedad costarricense en la última mitad del siglo veinte y principios del siglo veintiuno.

Palabras claves: memoria, barrio, valores, juegos tradicionales, creencias religiosas, cultura.

\begin{abstract}
This article deals with the memories and yearnings of a "neighborhood." This approach helps to develop a personal reflection on the socio-cultural changes -the way of living - that have happened in the Costa Rican society in the last half of the twentieth century and the beginning of the twenty-first.
\end{abstract}

Keywords: Memory, neighborhood, values, traditional games, religious beliefs, culture.

Recibido: 08 de setiembre, 2010 - Aprobado: 29 de junio, 2011

1 Máster y profesora de inglés de la Escuela de Literatura y Ciencias del lenguaje y del Liceo de Heredia de la Universidad Nacional. 
todos aquellos costarricenses que sobrepasamos los cuarenta
años de edad, nos sobresalta observar los cambios en la forma
de vida que se han dado en nuestra sociedad en la última mitad del siglo veinte y en los primeros años del siglo veintiuno. Cambios que, en general, podemos percibir en la tecnología, en la medicina, en el costo de la vida y en el ámbito político y militar a nivel internacional. Pero aún más preocupante, es el cambio radical que palpamos en los valores que nos identificaban como costarricenses, cambios que se perciben especialmente en nuestros niños y jóvenes, y/o jóvenes adultos. Esta transformación en la escala de valores de nuestros niños y jóvenes es lo que nosotros, los adultos, calificamos como pérdida de valores, porque ya no encontramos en las actuales generaciones las normas de respeto hacia los demás, los principios de solidaridad, de humanidad, cortesía y religiosidad entre otros.

Añoramos y recordamos aquellas vivencias en el 'Barrio', en donde se podía decir que todos nos conocíamos. Conocíamos al pulpero, al lechero, al zapatero y hasta al cura de nuestra iglesia, conociamos al borrachito del barrio y al chofer de la cazadora y ni qué decir del barbero. Era en las barberías en donde nuestros padres y jóvenes se deleitaban en la tertulia, tratando de arreglar el mundo o celebrando el gane de nuestro equipo de fútbol favorito. Éramos una sola familia: el vecino de al lado era con quién muchas veces compartíamos un poquito de azúcar o sal, le pedíamos hielo o un poquito de arroz y, en fin, hasta le confiábamos el cuidado de los chiquillos cuando saliamos al mercado o al Seguro Social.

En el barrio convivíamos personas provenientes de otros cantones de la misma provincia o nacidos ahí mismo. Era éste el lugar en donde se practicaba la solidaridad humana, unos siempre pendientes de los otros, algunos "metidos o vinas", pero al final, eran los mejores veladores en los funerales y los mejores rezadores en los rosarios del niño: todo con tal de tomar su buena aguadulcita o comer esas deliciosas quesadillas o rosquitas de almidón o maicena.

En nuestro barrio existían valores. La gente se saludaba en la calle, aunque no se conociera. Respetábamos a nuestros mayores, maestros y profesores. A mamá y a papá se les contestaba adecuadamente y, aunque a 'regañadientes', había que hacer los mandados. Los cafetales para jugar, la plaza, la iglesia, la 'pulpe', las calles, los potreros, la escuela 
y el cuadernito de vida, eran parte de nuestra vida cotidiana. Lo normal era que papá trabajara, mamá estuviera en la casa y los chiquillos en la escuela, en la casa o con los abuelitos.

Digamos que para entonces, todavía éramos un pueblo educado, con una pobreza muy particular porque el pobre del barrio, aunque pobre, no dejaba de comer. Su humildad y sencillez eran casi sinónimo de nuestra idiosincrasia y cultura. Chiquillos descalzos, nigüientos, piojosos o pulgosos, pero ahí íbamos, con el corazón rebosando de amor a la patria y a nuestras costumbres. No se escuchaba música metálica ni palabrillas como "maje o mae", más bien el que decía, en alguna ocasión, la palabrota 'hijuepu' era como el más malcriadillo del barrio, y nuestros padres nos prohibían andar con él o nos decian: "pase para adentro".

El Barrio, ese barrio. ¿Qué tenía que ver con nuestros valores y nuestra educación? ¿Cómo pensar, tantos años después, que le íbamos a añorar; qué le íbamos a recordar como cuna de nuestra educación y de nuestros valores? ¿En qué momento te perdimos ‘barrio’? ¿Eras acaso aquello que llamaban 'alma de los pueblos'?

¿Podríamos decir, entonces, que la existencia del ser costarricense había definido de cierta forma su idiosincrasia, que en realidad vivíamos inmersos en un mundo de pensamiento cristiano en donde el concepto de pecado era entendido como lo contrario a lo bueno, a la acción generosa de Dios? ¿Habremos virado drástica e inconscientemente nuestra existencia hacia un pensamiento modernista, orientado más que todo a la subjetividad, en donde simple y sencillamente vuelvo mi mirada al vecino de al lado y encuentro en él un ser que no conozco, que no sé ni cómo se llama ni de dónde viene, y a quien no me le acercaría para pedir un poquito de azúcar o sal, y mucho menos, alguien a quien confiaría el cuidado de mis chiquillos?.

¿Qué pasó con el 'barrio’? ¿Será esto lo que llamamos un giro antropológico, materialismo o evolucionismo? ¿Será que el mundo nos cambió? ¿Será ese cambio un ejercicio de nuestra propia libertad, de una escogencia razonada y pensada o más bien será que la corriente nos llevó, nos cambió, y destruyó nuestro barrio? ¿No es que la libertad es un don que Dios entrega al ser humano para que él escoja entre varias formas de bien? ¿Será que una mala escogencia nos quita la libertad, o simplemente que no escogimos, que nos llevó la corriente? 
Barrio, mi querido barrio, si después de tantos años hubiera sabido que me ibas a llevar a tantas interrogantes, posiblemente hubiera preferido quedarme en tus atardeceres de calles polvorientas y de chiquillos jugando 'quedó' en las calles o 'casita' en el 'guayabal'.

¿Pero cómo?... ¿Es así de malo ese cambio? Si bien ahora no existe el 'barrio', debe existir algo bueno en el entorno $u$ orden social en el que vivimos, y no debe ser todo pesimismo. Hoy nuestros pensadores utilizan términos que "suenan muy bonitos": pluralidad, socialización, escolarización. Estos conceptos vuelven hacia el desarrollo del hombre, hacia un mejor nivel de vida y una integración del ser humano, a las oportunidades de modernización, a mejores niveles de salud y ya no encontramos en nuestras escuelas chiquillos piojosos o con poliomielitis, sino niños sanos y educados. Ahora entendemos que como seres valemos mucho individualmente y podemos lograr nuestras metas. Se nos ha enseñado que depende de nosotros mismos lo largo que podamos llegar, frases como: "tus obstáculos son tan grandes o tan pequeños como tú mismo los quieras ver", "puedes llegar tan lejos como tú quieras", "valgo por lo que soy".

Qué bueno todo esto. Pero, si mi abuelito o abuelita pudiera salir a su puerta y mirar el atardecer de nuestros tiempos, posiblemente dirían: "iqué gente más egoista, ya no son capaces de pedir un poquito de azúcar a su vecino porque ahora todo lo pueden!. Dios guarde un rezo del niño o una vela de difunto, porque ni siquiera sabrian el nombre del muerto y se podrían equivocar. ¿Y las barberías? Ya no quedan más que unas cuantas y las que existen dicen ser "unisex beauty shops", y quienes atienden son personas con pelos teñidos y con nombres extranjeros como Frank o April.

Si les despertáramos de su eterno dormir, ¿podrían nuestros abuelos decirnos que hemos evolucionado? Más bien, creo que quedarían asombrados de observar que ya no se les saluda con un "buenos días" o "buenas tardes"; o de que ahora los hijos son desobedientes y demandan a los padres ante el Patronato de la Infancia o la Defensoría de los Habitantes, o incluso ante la Sala Cuarta. Esto y muchas cosas más posiblemente harían que nuestros abuelitos deseen volver a su dormir.

Pero, ¿por qué no entienden que evolucionamos, que somos libres, que todo cambió y que el barrio ya no importa? ¿Por qué no entienden que el hombre vale más ahora que antes, que el subjetivismo nos lleva a desarrollarnos individualmente para luego integrarnos a una 
sociedad ya pensada para nosotros, en donde ya no existe un barrio sino una globalización? Incluso, la idiosincrasia cristiana sigue existiendo, pero a nuestra manera, a como nos quede más cómodo, a lo que cada sujeto juzgue como pecado. ¡Qué bueno, ya no hay barrio, ya no hay valores, ahora soy yo y mi mundo, sigamos adelante! Ya no hay temor, respeto a Dios.

Pero, ¿subsistirá el alma, el alma del barrio? Sin querer entrar en la filosofia moderna occidental, en donde a partir de Grecia, se hacen algunos intentos por distinguir entre cuerpo y alma, existe una multiplicidad de términos filosóficos, antropológicos y epistemológicos que intentan definir los términos de espíritu y alma. Pero indudablemente sí creo que el Barrio llegó a tener vida y alma propia.

$\mathrm{Y}$ es aquí, en donde de nuevo podemos recordar aquellas lindas tardes en los regazos de nuestros abuelos, en donde al ponerse el sol y ver como los pajarillos buscaban su nido, nuestras abuelitas nos contaban que Dios tomaba una bolita de barro y soplaba sobre ella su aliento y salía un pajarito volando y que de igual manera nos hacía a nosotros a su imagen y semejanza soplando sobre nosotros su Espíritu Divino dándonos la vida, dándonos el alma. Tanto así que cuando el alma abandonaba el cuerpo, ese ser moría. Era como un fuego que al apagarse moría. El cuerpo, siempre concebido como el sepulcro del alma.

Como nos decían nuestros abuelitos, "la misión del hombre era liberar su alma por medio de la purificación", esto era una realidad esencialmente inmortal. De lo que el hombre hiciese en su vida, dependería su salvación y su caminar hacia la verdadera vida.

¿Podríamos decir entonces que aquel Barrio tenía alma propia? ¿Podríamos decir que el barrio era una entidad viviente con diferentes órganos como lo es un cuerpo humano? Si asi fuera, estaríamos asignando a nuestro añorado barrio una misión que debió de haber trascendido a los tiempos modernos. ¿Logró el barrio trascender, logró eternizarse? ¿Logró superar ese giro antropológico, el evolucionismo y materialismo? ¿Es que acaso esa "alma” del barrio anda vagante y se filtra entre lo moderno y lo antiguo, entre el subjetivismo y el pluralismo, entre lo material y lo intangible, en las políticas sociales, la salud y la educación?

Claro que sí, el barrio, el añorado barrio ya nos dejó, pero su alma, su espiritu, continúa aún encarnado en la mente y en los corazones de muchas personas que le han adoptado, personas que todavía quieren la 
purificación de sus espíritus para que su alma se haga inmortal, como la del barrio. Son personas caritativas, son profesionales, pensadores, estudiosos, políticos y trabajadores que hacen el bien, que viven sin hacer daño a los demás, que recuerdan a ese barrio y a todo lo que esa entidad involucraba, y que al igual que yo, le añoran. Personas que tratan de traerlo a la vida a través de sus propias vivencias con el buen ejemplo y la humildad, con la honestidad y la sinceridad, con el amor a los demás.

Y es que si no fuera así, el mismo sacrificio de Cristo, no tendría valor hoy. El Cristianismo define el "alma" como una vida, pero una vida superior a la biológica porque al fin es a ella a la que debemos cultivar para lograr ser inmortales, para que algún día regresemos a nuestra Patria, a nuestro añorado Barrio en donde los principios de solidaridad, de hermandad, de esfuerzo y de honestidad siempre están presentes. En donde aquellos valores que una vez nos dio El Barrio, continúen alimentando nuestras vidas espirituales.

Barrio, mi querido Barrio, si hubieras sabido que hoy ibas a ser el sujeto de mi ensayo universitario, posiblemente te vestirías de tus mejores galas, de tus mejores atardeceres y sacarías a correr por tus calles esa linda cazadora de asientos de madera, pintarías la fachada de la 'pulpe', abririas las puertas de la barbería para que más de un señor encuentre su refugio de habladurías, harías correr canicas por tus calles polvorientas y nos mostrarías al policía corriendo al borrachillo, al cuadernito de vida y a nuestra maestra con tiza en sus callosas manos, nos mostrarías a todos aquellos que en una Escuela Normal Superior estudiaban con el orgullo de ser futuros maestros, prominentes ciudadanos de los que dependía la Patria.

En fin, barrio, si hubieras sabido que hoy serías el sujeto de mi ensayo, serías mi oración completa y serias el verbo perfecto, serías por lo tanto, motivo de reflexión, Soplo Divino, fuego de vida e inspiración en nuestros profesionales.

Barrio, añorado barrio. 